\title{
Measurement of exposure to mouse urinary proteins in an epidemiological study
} Susan Gordon, Linda A Kiernan, M J Nieuwenhuijsen, A D Cook, Rosemary D Tee,
A J Newman Taylor
Department of Occupational and Environmental Medicine, Imperial College of Science, Technology, and Medicine, National Heart and Lung Institute, Manresa Road, London

$S$ Gordon

L A Kiernan

M J Nieuwenhuijsen

A D Cook

R D Tee

A J Newman Taylor

Division of

Cardiopulmonary

Biochemistry,

University College

London Medical

School, Rayne

Institute, 5 University

Street, London

L A Kiernan

Centre for

Environmental

Technology, Imperial

College, 48 Prince's

Gardens, London

M J N Nieuwenhuijsen

Correspondence to:

Dr S Gordon, Department of

Occupational and

Environmental Medicine,

Imperial College of Science

Technology and Medicine,

National Heart and Lung

Institute, Manresa Road

London SW3 6LR.

Accepted 6 August 1996

\begin{abstract}
Objectives-To develop an assay to measure airborne mouse urinary protein (MUP) and to assess the occupational exposure to MUP in the workforce of three establishments as part of an epidemiological study examining the influence of aeroallergen exposure on the development of allergic respiratory disease.

Methods-Personal air samples were collected from nine exposure groups during a workshift. A sensitive and reproducible competitive inhibition assay, which used rabbit antisera specific for MUP, was developed and used to measure the occupational exposure to MUP.

Results-The personal measurements of MUP showed that people with direct contact with mice (animal technicians) had the highest exposure followed in decreasing order by those working with anaesthetised animals or their tissue (postmortem workers and scientists) and those with indirect contact with mice (supervisors, office workers, and slide production workers). The only difference in concentrations of MUP between the three establishments were found for cage cleaners, which reflected differences in working practises for this exposure category. Air samples collected during the performance of specific tasks showed that high exposures to MUP were associated with handling mice, indirect contact with mice, and washing floors.

Conclusions-Exposure to mouse urinary proteins has been measured in the occupational environment. This information can be used to determine the relation between exposure to MUP and the development of allergic and respiratory disease.
\end{abstract}

(Occup Environ Med 1997;54:135-140)

Keywords: aeroallergen; mouse urinary proteins; occupational asthma

Allergy to laboratory animals is recognised as an important occupational health problem affecting nearly one third of those people who work with rats, mice, and other small mammals. ${ }^{1-4}$ Urine has been identified as an important source of the allergen in both rats and mice $^{5}$ and the major allergens have been described. ${ }^{6-8}$
The measurement of allergen in the working environment is of increasing importance as interest grows in controlling occupational exposure and in studying the influence of exposure to aeroallergen on the development of allergic disease. Several different immunological methods have been used to measure occupational allergens, the most common of which are radioallergosorbent test (RAST) inhibition (which uses the specific IgE antibodies in the serum of allergic subjects ${ }^{9}$ ) and assays which use rabbit antiserum which has been raised to the occupational antigen of interest. ${ }^{10}$ Although the RAST inhibition method has the advantage of measuring allergen (as opposed to generally immunogenic proteins measured by assays that use rabbit antiserum), it is thought to be a semiquantitative method. Both types of assays have potential long term reproducibility problems in that they use heterogenous antibody pools which may not be readily reproduced.

Although there is a growing body of information about occupational levels of both rat ${ }^{9-11}$ and mouse urinary aeroallergen, ${ }^{10-12}$ few studies have explored the relation between exposure to animal allergens and the development of allergic and respiratory disease. A seven year longitudinal study examining this relation at three institutions specialising in animal based research has been completed and the initial, cross sectional findings relating to exposure to rat aeroallergens have been reported. ${ }^{3}$ Data were also collected concomitantly to examine the influence of exposure to mouse airborne proteins on the development of respiratory disease.

In such exposure-response studies, an assessment of the efficacy of the techniques used to measure the environmental airborne allergen is essential. Of particular importance in the measurement of animal aeroallergens is the specificity of the immunoassay as there is known to be extensive cross reactivity between rat and mouse urinary proteins $\mathrm{s}^{15}$ and exposure to both species is common in the occupational environment. The accuracy and reproducibilty of the assay are also important factors in determining the final quality of the exposure data. This paper therefore describes the assay used to measure airborne concentrations of mouse urinary proteins (MUP) and assesses the specificity, accuracy, and reproducibility of the assay. The strategy used to assess the occupational exposure to MUP in the workforce of three establishments involved in animal based research is described and the exposures reported. 


\section{Material and methods}

ASSESSMENT OF ASSAY PERFORMANCE

Appendix 1 shows details of the immunological assay developed to measure MUP.

\section{Specificity}

The specificity of the assay was assessed by measuring the extent to which other antigens could inhibit the binding of the MUP specific antibodies used in the assay. Appendix 1 describes the assay of the standard mouse urine curve. In parallel, a serial dilution of rat urine antigen $(10000 \mu \mathrm{g} / \mathrm{ml}$ to $0.01 \mu \mathrm{g} / \mathrm{ml}$ in 10-fold dilutions) and a serial dilution of dust collected from the air conditioning system of a room housing mice $(100 \mu \mathrm{g} / \mathrm{ml}$ to $0.001 \mu \mathrm{g} / \mathrm{ml}$ in 10-fold dilutions) was also added to the assay system. The inhibition curves were statistically analysed for parallelism (described later).

\section{Accuracy and reproducibility}

The accuracy of the assay was examined by including control samples containing a known amount of MUP within each assay. The samples were made up independently of the standard curve antigen preparation (low $=0.005$ $\mu \mathrm{g} / \mathrm{ml} ;$ medium $=0.05 \mu \mathrm{g} / \mathrm{ml}$; high $=0.5$ $\mu \mathrm{g} / \mathrm{ml}$ ) and were stored in aliqouts at $-20^{\circ} \mathrm{C}$. These values were selected to fall on the expected linear part of the standard curve. Two sets of controls were assayed in duplicate on each microtitre plate throughout the course of the study. The difference between the target value and the measured value was taken as a measure of the accuracy of the assay. The reproducibility was assessed by statistically comparing the slope of the standard curve of 14 consecutive assays (as described in statistical methods), and by calculating the coefficients of variation within and between assays. The coefficient of variation between assays was calculated by determining the coefficient of variation of the percentage of inhibition data for each point of five independent standard curves each from a separate assay. The coefficient of variation within assays was similarly calculated from one standard curve repeated five times within one assay.

Effect of reconstitution and storage

Because of previous analyses for other aeroal- lergens, $37 \%$ of the samples had been reconstituted and stored for prolonged periods (mean (SD) $22.6(5.4)$ months) at $-20^{\circ} \mathrm{C}$. The effect of this storage was therefore examined; as two aliquots of each air sample were available (appendix 2), the MUP content of a freshly reconstituted aliquot was compared with that of the stored aliquot within the same assay.

\section{ASSESSMENT OF OCCUPATIONAL EXPOSURE TO} MUP

\section{Collection of air samples}

Air samples were collected with AFC 123 battery powered pumps fitted with seven holed sampling heads (Casella London, Kempston, Beds, UK) at $2 \mathrm{l} / \mathrm{min}$ on to polytetrafluoroethylene (PTFE) filters $(1.2 \mu \mathrm{m}$ pore size, 25 $\mathrm{mm}$, Sartorius Instruments, GB-Belmont, Surrey). The flow rate, as measured with a 0.5-5 1/min flow metre (Casella London; part number $\mathrm{A} 7652 / \mathrm{Z}$ ), was set at the beginning of sampling and checked at the end. The average flow rate was used to determine the volume of air sampled. If the flow rate varied by $>10 \%$ the sample was discarded.

\section{Air sampling strategy}

Three separate establishments participated in the study, only one of which (site C) worked exclusively with mice. Personal samples were collected from personnel who worked in departments where contact with mice (and rats for sites A and B) was possible. An occupational hygienist $(\mathrm{MJN})$ visited each site and divided the employees into nine exposure groups with the zoning strategy of Corn and Esmen $^{16}$ as guidance (table I). A sample of employees in each exposure group, selected with the aim of having sufficient numbers to include at least one of the workers within the highest $10 \%$ of exposures, were asked to wear the pumps for a full working shift (typically eight hours). Air samples were additionally collected at site A during five specific tasks; postmortem examination, handling of micefor example, during weighing, palpations, and checking for clinical signs - indirect contact for example, doing the daily checks of the mouse rooms and when replenishing food and water-floor washing, and working in corridors. Although the postmortem examinations

Table 1 Mouse urinary protein $n g / m^{3}$ by exposure group and site

\begin{tabular}{|c|c|c|c|c|}
\hline & Total & $\begin{array}{l}\text { Number of samples } \\
<\text { negative controls }\end{array}$ & $\begin{array}{l}\text { Arithmetic } \\
\text { mean (range) }\end{array}$ & $\begin{array}{l}\text { Geometric } \\
\text { mean }(95 \% \text { CI) }\end{array}$ \\
\hline \multicolumn{5}{|l|}{ Site A: } \\
\hline Office & 2 & 0 & $5 \cdot 4(5 \cdot 0$ to $5 \cdot 7)$ & $5 \cdot 3(4 \cdot 7$ to $6 \cdot 1)$ \\
\hline Animal technician & $7 \overline{3}$ & 11 & $108.9(2.1$ to 2382.5$)$ & $24.9(17.0$ to $36 \cdot 5)$ \\
\hline Scientist & 31 & 9 & $10 \cdot 1(2.0$ to $49 \cdot 1)$ & $7.2(5.3$ to 9.8$)$ \\
\hline Cage cleaner & 10 & 9 & $6.2(2.0$ to 42.0$)$ & $2.9(1.6$ to 5.3$)$ \\
\hline Supervisor & 5 & 3 & $8.9(2.5$ to 21.0$)$ & $6.6(2.9$ to 14.6$)$ \\
\hline Postmortem worker & 9 & 0 & $23.0(4.5$ to 106.9$)$ & $14.9(7 \cdot 1$ to $31 \cdot 2)$ \\
\hline Slide production & 30 & 28 & $2.8(1.5$ to 7.8$)$ & $2.7(2.3$ to 3.0$)$ \\
\hline Miscellaneous & 2 & 2 & $2 \cdot 3(2 \cdot 1$ to $2 \cdot 5)$ & $2 \cdot 3(2 \cdot 0$ to $2 \cdot 6)$ \\
\hline \multicolumn{5}{|l|}{ Site B: } \\
\hline Animal technician & 32 & 9 & $71.6(2.7$ to 994.8$)$ & $17 \cdot 9(11.2$ to $28 \cdot 7)$ \\
\hline Scientist & 10 & 8 & $21.9(2.4$ to 162.8$)$ & $6 \cdot 3(2.7$ to 14.9$)$ \\
\hline Cage cleaner & 6 & 0 & $244.3(22 \cdot 9$ to $587 \cdot 3)$ & $154.3(59.3$ to 401.0$)$ \\
\hline Maintenance & 1 & 0 & $87.9(87.9$ to 87.9$)$ & $87.9-$ \\
\hline \multicolumn{5}{|l|}{ Site C: } \\
\hline Office & 1 & 1 & $2.5(2.5$ to 2.5$)$ & $2 \cdot 5-$ \\
\hline Animal technician & 30 & 0 & $141.3(5 \cdot 3$ to $621 \cdot 6)$ & $7 \overline{8} \cdot 8(50 \cdot 3$ to $123 \cdot 3)$ \\
\hline Scientist & 14 & 3 & $28 \cdot 6(2 \cdot 2$ to $104 \cdot 5)$ & $14.0(6.7$ to 29.4$)$ \\
\hline Cage cleaner & 8 & 0 & $328 \cdot 1(11.5$ to 955.7$)$ & $139.7(45.8$ to $426 \cdot 1)$ \\
\hline
\end{tabular}


Figure 1 Specificity of the MUP inhibition assay and the validity of mouse urinary antigen as a standard for the airborne MUP measurement. Curves have not been fitted with a common slope.

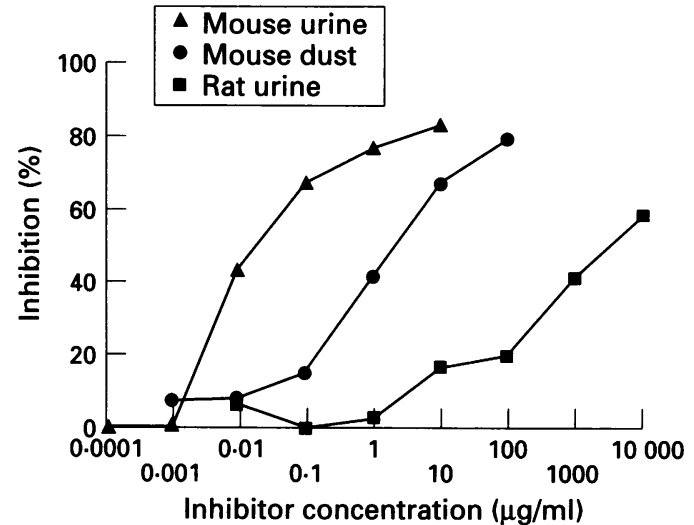

were performed by employees in the postmortem exposure group, all other tasks were performed by animal technicians.

\section{STATISTICAL METHODS}

Where comparisons were to be made between the inhibition curves generated by the antigen dilution series, the percentages of inhibition data for each of the curves were logit transformed and plotted against $\log _{e}$ concentration to form an approximately straight line. The regression line in each case was constructed from at least six points. Significant differences in the slopes of the lines were then tested by analysis of covariance (ANCOVA). The significance of the test was then obtained from $F$ tables.

The effect of prolonged storage at $-20^{\circ} \mathrm{C}$ was analysed by the method of Bland and Altman ${ }^{17}$; the difference between the paired measurements was plotted against the mean of the measurements, and the agreement in the values was compared. The significance of the difference was assessed with a paired $t$ test (Minitab, 3081 Enterprise Drive, State College, PA 16801, USA).

\section{Results}

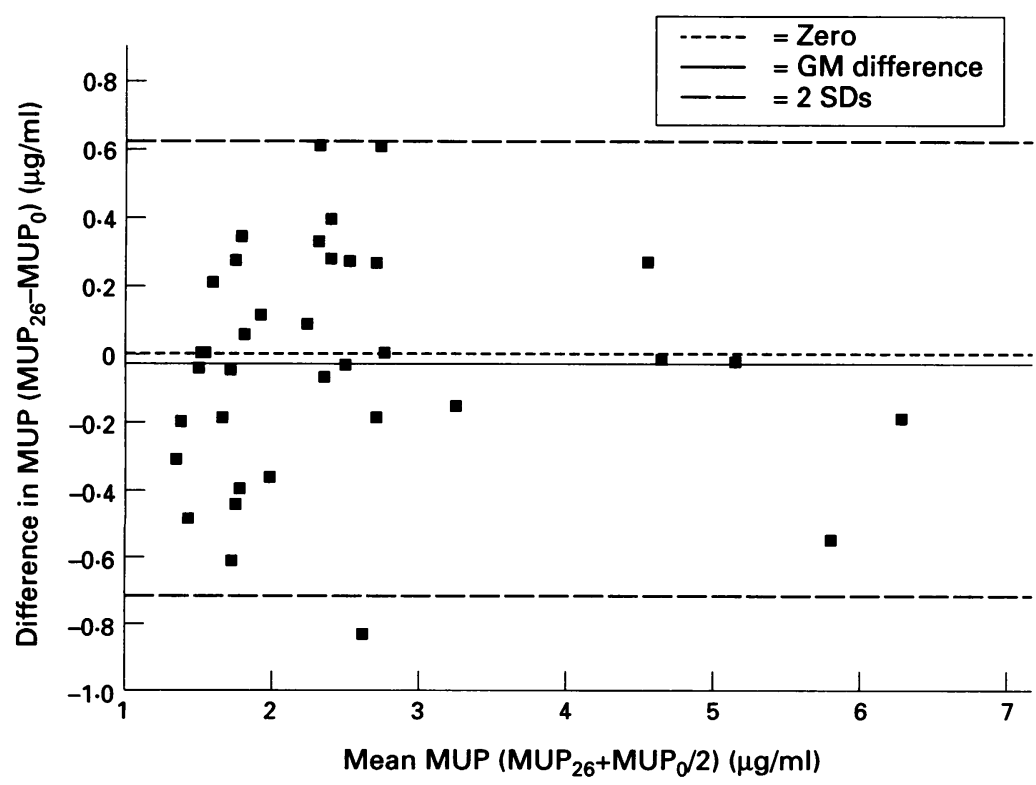

Figure 2 Comparison of concentrations of MUP measured in identical aliquots reconstituted 26 months before and immediately before assay.

\section{ASSAY PERFORMANCE}

Specificity

Mouse urine, rat urine, and mouse dust all gave dose-dependent inhibition in the MUP assay (fig 1). A common slope could not be fitted to all the curves $(P=0 \cdot 05)$, but when the rat urine data were removed, no significant difference was found between the slopes of the mouse urine and mouse dust inhibition curves $(P=0 \cdot 12)$. Mouse urine is therefore a suitable standard for the measurement of mouse airborne dust. Although formal analysis of the relative potency of the mouse and rat urine is inappropriate due to the non-parallelism of the inhibition curves, the rat urine inhibition curve is well displaced to the right of the mouse urine inhibition curve and therefore the presence of high concentrations of rat urinary aeroallergen (RUA) in the occupational environment will not interfere with the measurement of MUP indicating that the assay is highly specific for MUP

\section{Accuracy and reproducibility}

Of the three controls tested, only the medium control was consistently higher than the target value (low mean $=0.0057 \mu \mathrm{g} / \mathrm{ml}, \mathrm{n}=44$; medium mean $=0.0973 \mu \mathrm{g} / \mathrm{ml}, \mathrm{n}=44 ;$ high mean $=0.4912, \mathrm{n}=44$ ). A two way analysis of variance (ANOVA) of the data with both the assay and control type as variables showed that there was no significant difference in the values of the different assays $(P=0 \cdot 18)$. The MUP assay was highly reproducible; no significant difference was found between the slopes of the 14 consecutive logit transformed standard curves $(P=0.97)$. The coefficient of variation between assays varied between $6.14 \%$ and $20.0 \%$ for the assay range $(20 \%$ at $0.031 \mu \mathrm{g} / \mathrm{ml}$ ) and was greater than the coefficient of variation within assays (range $2 \cdot 10 \%$ $5.93 \% ; 5.93 \%$ at $0.31 \mu \mathrm{g} / \mathrm{ml}$ )

\section{Effect of reconstitution and storage}

The MUP concentration was measured for 36 samples in which one aliquot had been reconstituted 26 months previously (and the remaining eluate stored at $-20^{\circ} \mathrm{C} ; \mathrm{MUP}_{26}$ ) and the other aliquot reconstituted immediately before the assay $\left(\mathrm{MUP}_{0}\right)$. When the difference in the MUP values for each test sample $\left(\mathrm{MUP}_{26}-\mathrm{MUP}_{0}\right)$ was plotted against the mean value of the two measurements, there was close agreement between the MUP concentrations as shown by the distribution of the data points around zero (fig 2). The geometric mean (GM) difference between the paired MUP concentrations was 0.95 (fig 2, paired $t$ test, $\mathrm{P}=0.34$ ) and the $95 \%$ confidence interval (95\% CI) was 0.48 to 1.86 (fig 2). This shows that there was no notable deterioration in MUP concentration after reconstitution and prolonged storage at $-20^{\circ} \mathrm{C}$.

\section{EXPOSURE OF WORKFORCE}

Exposure groups

Of 290 personal shift samples collected, nine were unsuitable for analysis of MUP concentration due to filter irregularities or sampler breakdown. The final MUP concentration was 
Table 2 Mouse urinary protein $\left(n g / m^{3}\right)$ by task (from site A)

\begin{tabular}{lclcr}
\hline & Total & $\begin{array}{l}\text { Number of samples } \\
\text { <negative controls }\end{array}$ & $\begin{array}{l}\text { Arithmetic } \\
\text { mean (range) }\end{array}$ & $\begin{array}{l}\text { Geometric } \\
\text { mean (95\% CI) }\end{array}$ \\
\hline Postmortem worker & 7 & 0 & $7 \cdot 0(3 \cdot 1$ to $18 \cdot 2)$ & $5 \cdot 8(3 \cdot 6$ to $9 \cdot 3)$ \\
Handling & 12 & 0 & $309 \cdot 8(32 \cdot 6$ to $1513 \cdot 8)$ & $194 \cdot 3(112 \cdot 6$ to $335 \cdot 1)$ \\
Indirect contact & 25 & 0 & $150 \cdot 7(16 \cdot 4$ to $417 \cdot 8)$ & $104 \cdot 4(72 \cdot 4$ to $150 \cdot 5)$ \\
Floor washing & 4 & 0 & $93 \cdot 4(45 \cdot 0$ to 208.6) & $76 \cdot 2(39 \cdot 0$ to $149 \cdot 1)$ \\
Corridor work & 2 & 0 & $53 \cdot 5(33 \cdot 3$ to $73 \cdot 7)$ & $49 \cdot 5(22 \cdot 7$ to $107 \cdot 9)$ \\
\hline
\end{tabular}

not measured in a further 15 samples due to insufficient material. When repeated measurements on the same people are taken into consideration, the estimated proportions of the workforce sampled were; office workers $5 \%$, animal technicians $95 \%$, scientists $21 \%$, cage cleaners $98 \%$, supervisors $14 \%$ (site A only), postmortem workers $50 \%$ (site A only), slide production workers $71 \%$ (site A only), maintenance workers $50 \%$ (site B only), and miscellaneous workers $25 \%$ (site A only). The highest concentrations of MU? over a shift were experienced by those working directly with the animals or their soiled litter (animal technicians, table I). The lowest MUP concentrations were found in those with indirect contact with the mice or in those working only with their tissue (office based workers and slide production workers, table I). It is notable that $93 \%$ of the samples collected from the slide production workers at site A contained insufficient MUP to be detected and had to be assigned a value for statistical analysis to be possible (appendix 1). The variation in MUP concentrations within each exposure category was large.

\section{Site variation}

The MUP concentrations measured for each exposure category had a similar ranking in exposure at each site. The exception to this was the cage cleaners and the GM of the exposure at sites $A, B$, and $C$ respectively was 2.94 , 154.25 , and $139.67 \mu \mathrm{g} / \mathrm{ml}$. This variation probably reflects differences in working practices between the sites. At site A the personnel loaded cages that were previously emptied by the animal technicians, into the washing machine. At the other sites the cage cleaners both emptied the soiled litter from the cages and washed them.

\section{Task exposure}

Sixty nine task samples were collected of which 65 were analysed for MUP content (table 2); four filters were rejected because of sampling irregularities. The mean sampling times for handling mice, indirect contact, and cleaning out were 97, 66, and 33 minutes respectively, and MUP could be measured after only 20 minutes of indirect working with the mice. The sampling times for the postmortem examinations (mean $=573$ minutes) and miscellaneous tasks (mean $=573 \mathrm{~min}$ utes) were much longer. The highest exposure to MUP was measured among those handling the animals. Both handling the mice and indirect exposure to the mice were associated with higher MUP exposure than that for floor washing (table 2).

\section{Discussion}

This paper presents the first detailed assessment of the occupational exposure of research and animal house workers to mouse urinary proteins. These measurements were collected as part of a prospective study examining the relation between exposure to several different occupational aeroallergens and the subsequent development of respiratory disease.

In our previous report of occupational exposure to RUA, RAST inhibition was used to measure the airborne allergen..$^{910}$ The RAST inhibition could not be used here to measure mouse allergen due to the lack of allergic serum primarily sensitised to mouse. The specificity of the assay is of particular importance here as many of the air samples had been exposed to both rat and mouse. A competitive inhibition assay was therefore developed with rabbit antisera specific for MUP. Mouse urine was shown to be a suitable standard for the measurement of mouse exposure as shown by the parallelism of the mouse urine and mouse dust inhibition curves.

The competitive inhibition assay for MUP was shown to be more sensitive than the RUA RAST inhibition assay (detection limit of 0.5 $\mathrm{ng} / \mathrm{ml}$ for MUP $v 50 \mathrm{ng} / \mathrm{ml}$ for $\mathrm{RUA}^{10}$ ) but had comprable reproducibility (coefficient of variation between assays; $\mathrm{RUA}=7 \cdot 0 \%, \mathrm{MUP}=$ $6 \cdot 1 \%$ ). For the assessment of exposure to occupational allergens, an assay that has a low detection limit and a high reproducibility is essential; the low detection limit so that $(a)$ the allergen can be accurately measured for groups with low exposure to the allergen, and (b) that short sampling times can be studied, and high reproducibility so that many samples can be collected and processed over time without significant variation in the assay and hence the values obtained.

Long term storage of the reconstituted air samples for two years did not significantly alter the values in MUP measured. This may in part be due to the polyclonal nature of the immunological reagents used and the type of assay; if any deterioration of the MUP did occur while the reconstituted sample was in storage this did not seem to affect the inhibitory properties of the MUP epitopes in this assay system.

The data on exposure to MUP represent the average exposure experienced by personnel working with mice. The animal technicians had the highest exposure to MUP in all the sites. The MUP exposure of the cage cleaners was similarly high but dependent on the working practises adopted. The scientists and postmortem workers who generally worked with 
anaesthetised or dead animals had intermediate exposures, and all other workers had low exposure to MUP. The large variation in values on exposure to MUP within each exposure group and task category underlines the complexity of assessment for laboratory animal workers and is partly due to the nature of the work and the many determinants such as stock density and ventilation. ${ }^{18}$ Workers create their own working environment by spending variable durations performing different tasks in various small rooms with varying numbers of animals of different sex, age, and species, and varying levels of ventilation at different times. All of these factors may profoundly affect the exposure to laboratory animal allergens. ${ }^{8} 18$ Therefore, the grouping of workers could only be done crudely. This is thought to be unimportant for epidemiological research as long as there is limited overlap in exposure between groups. ${ }^{19}$ In future studies, repeated measurements from individual people will be taken to optimise the exposure grouping. ${ }^{20}$

Site $\mathrm{A}$, which used both rats and mice, was selected for the analyses of task specific exposure because it was the largest site participating in the study and had the most diverse range of procedures and exposure groups. Although in a parallel study of rat exposure nine task categories were identified and the exposure to RUA measured, ${ }^{9}$ only five tasks were undertaken with mice at the time of the present study. The four tasks not examined for MUP exposure were; no contact, slide production, experimental work on anaesthetised mice, and cage wash operators. In those tasks which were studied, it was found that both handling and indirect mouse contact were associated with higher exposures to MUP than was floor washing.

Previous reports of occupational exposure to mouse allergen have chiefly described the measurement of mouse allergen within mouse rooms (static sampling) rather than that experienced in the breathing zone of individual workers. ${ }^{1012}$ A smaller study by Ohman recently reported the exposure to Mus $\mathrm{ml}$ (the major mouse allergen) of 67 workers. ${ }^{13}$ Direct comparison of that study with our results are difficult due to differences in the purity of the mouse standard used, differences in sampling techniques, and the classification of workers, but both studies report exposure to most allergen in the $\mathrm{ng} / \mathrm{m}^{3}$ to $\mu \mathrm{g} / \mathrm{m}^{3}$ range. Like Ohman et al, ${ }^{13}$ we found low concentrations of MUP throughout the animal houses; personnel based in non-mouse containing rooms, such as offices, still had measurable exposure to MUP.

We have previously reported similar studies to measure the occupational exposure to RUA $^{9}$ and the same nomenclature has been used for the sites (A to $\mathrm{C}$ ), and the exposure groups, to enable comparisons to be made with our current findings. Although both the assays for RUA and MUP use urinary proteins as standards, the absolute concentrations between the assays cannot be compared directly due to the differences in the assay techniques. Although the MUP measured here was typically of the order of $\mathrm{ng} / \mathrm{m}^{3}$, that previously measured for RUA with RAST inhibition was three orders of magnitude higher $\left(\mu \mathrm{g} / \mathrm{m}^{3}\right)$. However, when each exposure zone is ranked according to decreasing exposure, the order of the zones is identical for both rats and mice (animal technician > postmortem worker $>$ scientist $>$ supervisor $>$ slide production workers). Although this suggests that qualitatively exposure to mice is similar to that of rats, the variation in the MUP exposures shown by the cage cleaners at the different sites clearly shows the importance of work practises in influencing exposures. Any parallels in the ranking of the exposure groups are therefore probably due to the similar nature of the allergens (primarily urinary in origin; particle size 5-15 $\mu \mathrm{m}$ ) and analogous working practises with the two species.

We have shown that it is possible to measure exposure to mouse urinary proteins in the occupational environment. This paper reports the first detailed study of exposure to MUP of a workforce and confirms that direct contact with mice is associated with the highest MUP exposures. The relation between work related symptoms and these quantitative MUP measurements is currently being examined with regression analysis.

This study has been funded jointly by grants from the Department of Health and Social Security, the Health and Safety Executive, and the National Asthma Campaign. The Royal Society supported the purchase of the air sampling equipment. We thank Miss Jennifer Welch for the expert eluequipment. We thank Miss Jennifer Welch for the expert eluserum and Dr Colin Sandiford for purifying it.

\section{Appendix 1: Assay of mouse urinary protein} (MUP)

REAGENTS

Urine was collected in a metabolism cage from adult male mice and rats. The urine was filtered (grade 1, Whatman International, Maidstone, Kent), concentrated with an Amicon CH2A hollow fibre system (Amicon, Gloucestershire), dialysed in visking tubing (Medicell International, London) over 48 hours against four changes of distilled water, and lyophilised. Dust was collected from the air conditioning system of a room housing only mice at site $\mathrm{C}$ and was extracted in $0 \cdot 1 \mathrm{M} \mathrm{NH}_{4} \mathrm{HCO}_{3}$ overnight, the supernatant dialysed, and lyophilised as above.

Antimouse urine antiserum was raised in rabbits (female, New Zealand whites, Foxfield Farms UK, Petersfield, Hampshire). The rabbits $(n=2)$ were initially injected subcutaneously with $1.0 \mathrm{ml}$ of $1.0 \mathrm{mg} / \mathrm{ml}$ mouse urine in 50:50 $0.154 \mathrm{M}$ sodium chloride: Freund's complete adjuvant (Sigma, Poole, Dorset). Booster injections were repeated every four weeks, replacing the Freund's complete adjuvant with incomplete adjuvant. The serum was collected about 6-10 days after each injection and the serum from bleeds 2 to 7 inclusive were pooled. The pooled antiserum samples were purified with the caprylic and ammonium sulphate precipitation method of McKinney and Parkinson, ${ }^{21}$ then dialysed against $0.015 \mathrm{M}$ phosphate buffered saline (PBS) and lyophilised.

\section{ASSAY METHOD}

Immunolon II removawell strips (Dynatech Laboratories, Billingshurst, West Sussex) were coated overnight at $4^{\circ} \mathrm{C}$ with $200 \mu \mathrm{l}$ per well of $10 \mu \mathrm{g} / \mathrm{ml}$ mouse urine antigen in $0.05 \mathrm{M}$ sodium carbonatesodium hydrogen carbonate buffer (pH 8.0). The wells were washed four times with RAST washing buffer (Pharmacia Diagnostics, Uppsala, Sweden). A standard inhibition curve was created by adding mouse 
antigen (100 $\mu \mathrm{l}$ per well in triplicate) from $2 \mu \mathrm{g} / \mathrm{ml}$ to $0.5 \mathrm{ng} / \mathrm{ml}$. Air samples $(100 \mu \mathrm{l})$ and controls $(100 \mu \mathrm{l}$; low, $5 \mathrm{ng} / \mathrm{ml}$; medium $50 \mathrm{ng} / \mathrm{ml}$; high $500 \mathrm{ng} / \mathrm{ml}$ ) were assayed in duplicate. Purified antimouse antiserum (diluted to $1 \mu \mathrm{g} / \mathrm{ml}$ in PBS diluent; $100 \mu \mathrm{l}$ per well) was added to all antigen containing wells and the plate incubated at $4^{\circ} \mathrm{C}$ for four hours. Finally the wells were washed, $100 \mu 1$ of :25I labelled protein-A (10 ng/ml, Amersham International, Amersham, Buckinghamshire) added to each well, and after a further two hour incubation at room temperature, the plates were washed and the wells counted individually in a COBRA auto-gamma counter (model 5005, Canberra-Packard, Pangbourne).

CALCULATION OF CONCENTRATION OF AIRBORNE MUP The standard curve was constructed from 12 data points with a four parameter logistic curve fit, and the MUP concentration [MUP $\mathrm{ng} / \mathrm{ml}$ ] of the controls and air samples automatically interpolated. The MUP concentration of the air sample was then calculated as:

$$
\operatorname{MUP}\left(\mathrm{ng} / \mathrm{m}^{\mathrm{i}}\right)=\frac{[\mathrm{MUP} \mathrm{ng} / \mathrm{ml}] \text { reconstituted volume }(\mathrm{ml})}{\text { volume of air sampled }\left(\mathrm{m}^{3}\right)}
$$

CRITERION FOR THF ACCEPTANCE OF AIR SAMPLE RESULTS

The maximum variation allowed between the duplicate counts for each test sample was $5 \%$ and 55 samples $(19 \%)$ were therefore repeated. Samples still failing this quality control measure were repeated up to three times and the mean value taken $(n=19)$. Test samples containing $>500 \mathrm{ng} / \mathrm{ml}$ were diluted and reassayed.

The detection limit for the assay was $0.5 \mathrm{ng} / \mathrm{ml}$, equivalent to approximately $0.315 \mathrm{ng}$ MUP per filter, but no filters fell into this category. However, negative control air samples, which were filters kept in the sampling head during the sampling period without the pump running, registered low concentrations of MUP $(\mathrm{n}=11$, arithmetic mean $=3.96 \mathrm{ng})$. For statistical purposes, air sample eluates containing MUP of $<3.96$ $\mathrm{ng}$ were therefore assigned a value of $1.8 \mathrm{ng}$ (half of the difference between the detection limit of the assay and the negative control samples ${ }^{22}$ ) and corrected for the volume of air sampled $(n=83)$. All filters containing MUP $>3.96 \mathrm{ng}$ were regarded as being positive and the measured value was reported.

\section{Appendix 2: Filter elution method}

Filters were eluted for two hours in test tubes with $0 \cdot 1$ $\mathrm{M}$ ammonium hydrogen carbonate $\left(\mathrm{NH}_{4} \mathrm{HCO}_{3}\right)$ buffer containing $0.5 \% \mathrm{v} / \mathrm{v}$ Tween 20 , and were vortexed at 0 , 1 , and 2 hours. ${ }^{23}$ The eluates were centrifuged at 2500 $\mathrm{rpm}$ for 10 minutes and the supernatant aliquoted $(\mathrm{n}=$ 2), lyophilised, and stored at $-20^{\circ} \mathrm{C}$. Air sample extracts were reconstituted in PBS diluent $(0 \cdot 1 \mathrm{M}$ PBS with $0.3 \% \mathrm{w} / \mathrm{v}$ human serum albumin and $0.1 \% \mathrm{w} / \mathrm{v}$ sodium azide).

1 Venables KM, Tee RD, Hawkins ER, Gordon DJ, Wale CJ, Farrer NM, et al. Laboratory animal allergy in a pharmaceutical company. $\mathrm{Br}$ f Ind Med 1988;45: 660-6.

2 Aoyama K, Ueda A, Manda F, Matsushita T, Ueda T,
Yamauchi C. Allergy to laboratory animals: an epidemiological study. Br F Ind Med 1992;49:41-7.

3 Cullinan P, Lowson D, Nieuwenhuijsen MJ, Gordon S, Tee RD, Venables KM, et al. Work-related symptoms, sensitisation, and estimated exposure in workers not presensitisation, and estimated exposure in workers not pre-
viously exposed to laboratory rats. Occup Environ Med viously exposed
$1994 ; 51: 579-58$.

4 Renström A, Malmberg P, Larsson K, Sundblad B-M, Larsson PH. Prospective study of laboratory animal allergy: factors predisposing to sensitisation and development of allergic symptoms. Allergy 1994;49:548-52.

5 Newman Taylor AJ, Longbottom JL, Pepys J. Respiratory allergy to urine proteins of rats and mice. Lancet 1977;ii: $847-9$.

6 Longbottom JL. Characterisation of allergies from the urines of experimental animals. In: Kerr JW, ed. Proceedings of the XIth International Congress on Allergology and Clinical Immunology. London: Macmillan Press, and Clinical

7 Longbottom JL, Price JA. Allergy to laboratory animals characterisation and source of two major mouse allergen $\mathrm{Ag} 1$ and $\mathrm{Ag} 3$. Int Arch Allergy' Clin Immunol 1987;82 $450-2$

8 Gordon S, Tee RD, Newman Taylor AJ. Analysis of rat urine proteins and allergens by sodium dodecyl sulfatepolyacrylamide gel electrophoresis and immunoblotting. $\mathcal{7}$ Allergy Clin Immunol 1993;92:298-305

9 Gordon S, Tee RD, Nieuwenhuijsen MJ, Lowson D, Harris J, Newman Taylor AJ. Measurement of airborne rat urinary allergen in an epidemiological study. Clin Exp Allergy 1994;24:1070-7.

10 Price JA, Longbottom JL. ELISA method for measurement of airborne levels of major laboratory animal allergens Clin Allergy 1988;18:95-107.

11 Nieuwenhuijsen MJ, Gordon S, Tee RD, Venables KM, $\mathrm{M}$ 'Donald J, Newman Taylor AJ. Dust and rat urinary aeroallergen exposure in animal houses. Occup Environ Med 1994;51:593-6.

12 Twiggs JT, Agarwal MK, Dahlberg MJE, Yunginger JW Immunochemical measurement of airborne mouse allergens in a laboratory animal facility. 7 Allergy Clin Immunol 1982;69:522-6.

13 Ohman JL, Hagberg K, MacDonald MR, Jones RR, Paigen BJ, Karcergis JB. Distribution of airborne mouse allergen in a major breeding facility. 7 Allergy Clin Immunol in a major bre

14 Corn M, Koegel A, Hall T, Scott A, Newill C, Evans R. Characteristics of airborne particles associated with animal allergy in laboratory workers. Ann Occup Hyg 1988;32(suppl 1):435-46.

15 Gordon S, Welch JA, Tee RD, Newman Taylor AJ. Allergenic cross-reactivity between rat and mouse urine. Clin Exp Allergy 1994;24:176.

16 Corn M, Esmen NA. Workplace exposure zones for classification of employee exposures to physical and chemical agents. Am Ind Hyg Assoc f 1979;40:47-57.

17 Bland JM, Altman DG. Statistical methods for assessing agreement between two methods of clinical measureagreement between two metho

18 Nieuwenhuijsen MJ, Gordon S, Harris J, Tee RD, Venables KM, Newman Taylor AJ. Determinants of airborne allergen exposure in an animal house. Occup Hyg 1995;1:317-24

19 Heederik D, Kromhout H, Burema J. Assessment of longterm exposure to toxic substances in the air. Ann Occup Hyg 1991;35:671-3.

20 Kromhout H, Loomis DP, Kleckner RC, Savitz DA Sensitivity of the relationship between cumulative magnetic field exposure and brain cancer to choice of exposure grouping scheme. Epidemiology 1995;6:S118.

21 McKinney M, Parkinson A. A simple non-chromatographic procedure to purify immunoglobulins from serum and ascites fluid. F Immunol Method 1987;96: $271-8$

22 Hornung RW, Reed LD. Estimation of average concentration in the presence of non-detectable values. Occup Environ Hyg 1990;5:46-51.

23 Gordon S, Tee RD, Lowson D, Newman Taylor AJ. Comparison and optimization of filter elution methods for the measurement of airborne allergen. Ann Occup Hyg 1992;36:575-87. 